\section{Drug misuse and sharing of needles in Scottish prisons}

\author{
Dermot H Kennedy, Gwyneth Nair, \\ Lawrence Elliott, Jason Ditton
}

\section{Department of Infection} and Tropical Medicine, Ruchill Hospital, Glasgow G20 9NB

Dermot H Kennedy, FRCP, consultant physician

\section{Criminology Research Unit, University of Glasgow, Glasgow G12 8QQ \\ Gwyneth Nair, PHD, research fellow \\ Jason Ditton, PHD, director}

HIV and AIDS Resource Centre, Ruchill Hospital, Glasgow G20 9NB

Lawrence Elliott, MA, research officer

Correspondence to: Mr Elliott.

BMF 1991;302:1507

Department of Psychology, University of Stirling,

Stirling FK9 4LA

K G Power, PHD, principal clinical psychologist

I Markova, PHD, professor of psychology

A Rowlands, MPHIL principal clinical psychologist $\mathrm{K} \mathrm{J}$ McKee, PHD, research fellow

P J Anslow, MA, research assistant

\section{Department of}

Psychological Medicine,

University of Glasgow

C Kilfedder, MAPPSCI,

clinical psychologist

Correspondence to:

Dr Power.

BMF 1991;302:1507-8
More than a half of the people in Scotland with known HIV infection are drug injectors. ${ }^{1}$ Two recent studies have suggested that injecting with a consequent risk of HIV transmission is prevalent among drug misusers in prison. ${ }^{23}$ There is also concern over the lack of treatment for drug misuse in prison. ${ }^{+}$Drug misusers attending needle exchange centres seem able to maintain a low level of risk behaviour, ${ }^{5}$ although their attendance may be interrupted by imprisonment. ${ }^{3}$ Little is known about their drug taking, injecting, and sharing of needles in prison.

\section{Subjects, methods, and results}

A questionnaire was administered to 81 drug injectors at two Glasgow needle exchanges in January 1990. Semistructured indepth interviews were conducted with another 19 injectors at the same exchanges in June 1990.

Of the 81 injecting drug misusers $(61$ men and 20 women), $56(69 \%)$ had served at least one term in custody (median 5 terms, range 1-40), of whom 39 (31 men and 8 women, mean age 23.7 years) had served their most recent sentence during 1989. Of the 56 former prisoners, 55 were aware that other inmates had misused drugs and 36 said that they themselves had misused drugs in prison. Only four $(11 \%)$ of those misusing drugs in prison had taken cannabis alone. Other drugs taken were buprenorphine, temazepam, heroin, cocaine, and valium. Forty nine had seen other inmates injecting drugs, and 14 men said that they themselves had injected drugs in prison. Forty five had seen others sharing needles in prison, and six said that they themselves had shared needles in prison. This means that $43 \%$ (six of the 14) of those admitting to injecting also shared needles.

Fifty one subjects said that they had not been offered treatment for drug problems while in custody, although 46 stated that the prison authorities knew that they were drug misusers. Four of the eight women had been offered some form of treatment for withdrawal symptoms, but 47 of the 48 men said that they had not been offered any treatment.

\section{Sexual behaviour in Scottish prisons}

\author{
K G Power, I Markova, A Rowlands, \\ K J McKee, P J Anslow, C Kilfedder
}

Attention has recently focused on the issue of HIV in prisons. 'The Prison Reform Trust suggests that up to $20-30 \%$ of long term prisoners may engage in homosexual acts. ${ }^{2}$ Moreover, some prison officers reportedly believe that up to $60 \%$ of inmates participate in homosexual acts. ${ }^{3}$ This supposed high incidence of homosexuality within prisons has led to recommendations for the issuing of condoms to male inmates. Unfortunately, all reports regarding sexual behaviour of inmates are anecdotal, and calls for more detailed investigations have been made. ${ }^{5}$ Furthermore, little
All 81 subjects were asked whether they might inject and share needles in prison in the future. Sixty seven thought that they would misuse drugs and 55 that they would inject them; 20 thought that they would share injecting equipment. These figures are higher than those reported for actual misuse, injecting, and sharing needles.

\section{Comment}

This study shows that most drug injectors attending Glasgow needle exchanges have been in prison. Six subjects $(11 \%)$ admitted to sharing needles in prison. The true extent of sharing may be greater as the other eight who reported injecting drugs in prison were unlikely to have had exclusive access to their own equipment. Respondents in the semistructured interviews emphasised this fact-"When you hide your needle, someone else might find it and it gets used in their circle, so you can't say how many get to use it." Estimates of the number of people sharing one needle varied between five and 100. It therefore seems highly probable that when a drug misuser shares needles inside prison, this may occur more frequently and among a wider group of people than it would outside prison.

Little treatment seems to be offered for drug problems in Scottish prisons. Fifty one $(91 \%)$ respondents said they had received no treatment at all. This contrasts with a recent study that found that only $40 \%$ of a group of 50 drug misusers in London had not received treatment while in custody. ${ }^{2}$ This apparent lack of treatment offered in Scottish prisons, together with the prevalence of reported injecting drug misuse and sharing of needles are matters of serious concern.

This study was funded by the Nuffield Foundation, London. We thank Kathryn Farrow and Sam Phillips for their help with data collection and preparation.

1 Communicable Diseases (Scotland) Unit. ANSWER (AII)S newes supplement, DS weekly report). Glasgow: CDS Unit, Ruchill Hospital, 1990. Report No $90 / 28$

2 Carvell ALM, Harl (iJ. Risk behaviours for HIV infection among drug users in prison. B.117 1990:300:1383-4.

Dolan KA, Donoghoe MC, Stimson GV. Drug injecting and svringe sharing in custody and in the community: an exploratory survey of HIV risk behaviour. The Howard foumal 1990:29:177-86.

4 Harding TW. HII\%AIISS in European prisoms. Geneva: World Health Organisation. 1990.

5 Stimson (iV. Infecting equipment exchange schemes. Final report of the monitoring research group. London: University of London, 1988.

Accepted 27 March 1991

has been said regarding the issue of female sexual behaviour in prison.

\section{Subjects, methods, and results}

From a total of roughly 4800 inmates, a group of 559 (representing $11.7 \%$ of the total Scottish prison population and a response rate of $86.4 \%$ ) were recruited from eight penal establishments. This random stratified sample was chosen on the basis of representing the three main categories among male and female prisoners - namely, remand $(\mathrm{n}=190)$; short term, serving less than three years $(n=205)$; and long term, serving three years or more $(n=164)$. Inmates were interviewed in privacy. Before participation they were informed that the survey was part of a series of studies concerned with assessing knowledge and attitudes with respect to HIV and AIDS. They were also informed that more personal information regarding sexual behaviour and intravenous drug use would also be required. We 